\title{
Um fio que tece a história infância
}

\begin{abstract}
Resumo: O que levaria as crianças que ainda não leem a debruçarem sobre as histórias infantis, sobre os contos de fadas? Será que há uma possibilidade de leitura que extrapola a decodificação? Que leitura seria essa? O que essas crianças estariam lendo nesses portadores de texto? Poderíamos considerálas leitoras? Essas questões norteiam o desenvolvimento da temática apresentada neste texto cujo objetivo é discutir o interesse, por parte das crianças, pelo enredo dos contos infantis. Para dar conta dessa discussão, alguns passos tornam-se fundamentais, tais como: definir os conceitos de leitura e leitor, estabelecer a relação entre as produções imaginárias e as histórias de leitura e, consequentemente, a importância destas para a aprendizagem e a constituição da subjetividade.

Palavras-chave: Leitura. Imaginário infantil. Subjetividade.
\end{abstract}

\section{Ouvindo histórias}

Era uma vez uma menina que vivia numa aldeia e era a coisa mais linda que se podia imaginar. Sua mãe era louca por ela, e a avó mais louca ainda. A boa velhinha mandou fazer para ela um chapeuzinho vermelho, e esse chapéu the assentou tão bem que a menina passou a ser chamada de Chapeuzinho Vermelho. (PERRAULT, 1994, p. 51)

Quem já não foi apresentado, durante a infância, à menina do capuz vermelho, ao lobo que tem a boca tão grande, ao porquinho da casa de palha, ao boneco que mentia, ao menino que não queria crescer? Quem já não ouviu uma história com princesas, madrastas, fadas ou bruxas?

Pensar nessas histórias, certamente, remete a crianças pequenas, a colocar filhos para dormir ou a lembranças vagas, pedaços da própria infância, quando se esperava, ansiosamente, o dia, o momento de ouvir novamente aquela história que podia ser contada pela mãe, pelo pai, pela professora ou até mesmo, quem sabe, por um irmão.

Por outro lado, na rotina diária das escolas, nas salas das crianças pequenas, em especial, não é surpresa encontrarem-se livros de Os três porquinhos, Cinderela, A Branca de Neve, por exemplo, esperando para serem folheados, manuseados, abertos, lidos, relidos, prontos para serem "devorados" por aqueles pequenos leitores. Nesses espaços, em vários momentos, não é raro observar esses pequenos aprendentes, olhos fixos nas
Leila da Franca Soares

Professora substituta da Faculdade de Educação

Universidade Federal da Bahia 
imagens, a escutarem o enredo, em silêncio, fisgados pela magia, pelo mundo de encantamentos e de maravilhas que ali se conta. E, então, apenas ouvimos as suas vozes, quando precisam tecer comentários, fazer perguntas ou repetir trechos da história, o que quase sempre fazem com precisa fidelidade.

De alguma forma, todos nós já ouvimos esse tipo de narrativa, em algum momento de nossas vidas. O fato é que ele existe e sobrevive até hoje. Poderíamos perguntar, então, sobre o quê de extraordinário existe neste tipo de história para conseguir ultrapassar décadas, sem perder a atualidade da magia. Por que caminho os contos de fadas conseguem atingir o leitor? Por qual via conseguem trazer a chave, como diz Marisa Lajolo, até o leitor?

Do aluno obrigado a escrever uma redação que lhe garanta nota mínima na prova, ao festejado autor de best-sellers milionários, o trazer ou não a chave é senha para cativar leitores: tanto o professor que encomenda a redação quanto o público que deve consumir o romance, ambos precisam encontrar, no texto que lêem, o que nele foram buscar: se encontram mais do que esperavam, melhor para eles; se encontram menos, pior para o autor que pode ter perdido, no desencanto do desencontro, seu precioso leitor. (LAJOLO, 2005, p. 33-34)

O estudo define como "leitoras", as crianças da Educação Infantil, apesar de considerar que elas não estão ainda aptas para a decodificação de palavras. Talvez muitas delas, inclusive, nem saibam, ainda, todas as letras do alfabeto e não deem conta de uma escrita alfabética, mas é que se trata, aqui, e da leitura que vai além do reconhecimento, da soletração, da emissão de sons, da decodificação. Fala-se, aqui, de "leitores" que conseguem extrair do texto algo a que atribuem sentido para si, que encontram nele algo que procuram em sua trajetória na busca de conhecimento, mas que vai além do aparente, do simples fenômeno.

Assim, o estudo considera que essas crianças da Educação Infantil são pequenos sujeitos de conhecimento e aprendizagem que se situam num período em que as "histórias de leituras" acontecem e, possivelmente, influenciam, na sua formação como leitoras. As histórias contadas, o lugar que estas ocupam para quem conta e para quem ouve, o acesso aos diversos portadores de textos, desencadeiam a relação que vai sendo tecida com a leitura - indícios disso irão aparecer, mais tarde, na relação futura com a leitura, no gosto ou não por esta.

16 R. Faced, Salvador, n.14, p.15-25, jul./dez. 2008 
Entretanto, é preciso considerar, desde já, que as histórias de leituras são importantes na formação desse sujeito-leitor, mas que deve haver espaço também para a busca de outros caminhos que ali possa trilhar, quando manifesta sua escolha, seu desejo em outra direção. Ou seja, é necessário esclarecer que não se trata de identificar uma relação linear, sem saídas, da criança com a leitura: se, por exemplo, uma criança formada num ambiente onde a leitura não aparece, ou não tem a importância devida, não the sendo possível mergulhar no mundo de Harry Potter, ou deliciarse com as aventuras de Monteiro Lobato, por ser um sujeito ativo, permeado pelo desejo, será capaz de encontrar formas outras, singulares, de fazer o caminho do leitor.

\section{Lendo nas entrelinhas}

[...] passei a infância em uma casa sem livros, sempre com a sensação de que eles não me pertenciam. O livro não era espaço em que podia ficar impressa minha marca de possuidor. E a escola acabou figurando, para mim, como lugar vazio e desimportante. Tudo que ela nos transmitia virava pozinho de borracha, sujo de grafite, no fim do ano.

A partir de meu contato com a biblioteca pública da cidade, formei-me leitor e, quando

saí de casa, levei orgulhosamente algumas dezenas de livros comprados meio escondidos.

(SANCHES NETO, 2004, p. 14)

Marisa Lajolo (2005) define ler para além de decodificar: para ela, ler é poder, a partir de um texto, construir relações com outros textos significativos, é poder criar sentido. Que sentido é esse a que somos remetidos enquanto leitores? Poder-se-ia estabelecer, aqui, uma relação possível entre sentido e desejo ${ }^{1}$ ? Poder-se-ia dizer, por exemplo, que o que está para além do aparente seria algo que nem mesmo sabemos por que nos interessa? Será que caberia fazer, aqui, uma relação com aquelas expressões do tipo: já li, várias vezes, o Pequeno príncipe, mas não suportei Pinóquio. Ou não consigo terminar de ler aquele capítulo que é necessário para a prova; ou, ainda: não gosto de ler, ou não consigo parar de ler esse romance?

Parece que é possível construir várias relações com o livro, com a leitura, e parece também que muito do que se forma nessas

(1) Desejo, s.f.(alem.: Begierde. Begehren, Wunsch; fr.: désir; ing.: wish). Falta inscrita na palavra e efeito da marca do significante sobre o ser falante. Em um sujeito, o lugar de onde vem sua mensagem lingr de onde vem sua mensagem parental ou social. Ora, o desejo do parental ou social. Ora, o desejo do sujeito falante é o desejo do Outro. Constitui-se a partir dele, é uma falta articulada na palavra e é a linguagem que o sujeito não poderia ignorar, sem prejuízos. Como tal, é a margem que separa, devido à linguagem, o sujeito de um objeto supostamente perdido. Esse objeto supostamente perdido. Esse objeto do fantasma do sujeito. (CHEMAMA, 1995, p. 42) 
relações conseguimos identificar, mas ficam outros elementos que se perdem, que se tornam inacessíveis nessa construção. Por outro lado, também sabemos que esses elementos aparecem e se mostram, dando prova da sua existência. O que é preciso saber é por que buscamos determinadas leituras e afastamos outras. Há o livro que, só de olhar, nos seduz, nos chama, nos convida e quase nos arrebata, obrigando-nos a neles mergulhar; há outros dos quais passamos longe, evitamos, até, passam dias com o marcador na mesma página, sem chance alguma de obter um lugar melhor nas nossas prioridades. Livro, às vezes, lembra infância, que lembra brincar, que lembra fantasia, que lembra imaginação, maravilha, encantamento; também lembra escola, leitura, escrita e, às vezes, obrigação e tédio.

Seguindo por esse ponto de vista, segundo o qual cada um extrai da leitura o sentido que faz conexão consigo mesmo, fazendo aparecer respostas temporárias a questionamentos próprios, a inquietações cruciais, poder-se-ia, então, pensar que essas crianças pequenas de que se trata o estudo poderiam estar lendo o que precisam decodificar? Poder-se-ia dizer que elas estariam lendo o que estão procurando, isso que está além do que está nas letras, mas cria possibilidade de brechas, de espaços de elaboração, sobre aquilo a que, aparentemente, não é possível de ter acesso, mas que faz falta, faz verdade, talvez, para elas?

Ainda seguindo o mesmo raciocínio, estariam tais leitores, interessados apenas na leitura de imagens, nas ilustrações, na apresentação do portador de texto ou no enredo das histórias? Poder-se-ia pensar que, para elas, tanto faz, por exemplo, ler Chapeuzinho Vermelho ou A Branca de Neve e Os Sete Anões? Mas, então, por que algumas crianças pedem para repetir, por várias vezes, a mesma história? Procurariam elas, naquele momento, algo que encontrariam, por exemplo, no lobo, mas não nos anões? Interessaria a elas ouvir dizer que o lobo comeu Chapeuzinho, tanto fazendo saber que o príncipe salvou a Branca de Neve?

Indo por esse caminho, o estudo não estaria tocando algo somente lido nas entrelinhas do texto por determinado sujeito e que não seria visto ou não interessaria a outro? Mas, nesse caso, a leitura não se faria apenas por existir um texto, mas pela relação existente entre este e o leitor, o que ultrapassa a definição de leitura como decodificação, como um ato meramente mecânico. E mesmo em se tratando de algo que interessa a um coletivo,

18 R. Faced, Salvador, n.14, p.15-25, jul./dez. 2008 
existiriam possíveis caminhos a serem percorridos, singularmente, por cada um que o integra.

Eni Orlandi, em seu livro Interpretação: autoria, leitura e efeitos do trabalho simbólico, aborda e discute sobre a questão da interpretação em qualquer forma de discurso, sobre os seus lugares, sua forma, sua natureza e seu funcionamento. Ela afirma que não há sentido sem interpretação, concluindo que "[...] o espaço da interpretação é o espaço do possível, da falha, do efeito metafórico, do equívoco, em suma: do trabalho da história e do significante, em outras palavras, do trabalho do sujeito". (ORLANDI, 2004, p. 22)

Assim, chega-se a alguns pontos interessantes. Primeiramente, percebe-se que a citação de Orlandi introduz a relação entre interpretação e o espaço da falha, da metáfora, do equívoco, do trabalho do sujeito, o que encoraja dizer que essa forma de conceber a interpretação cria a possibilidade de trazer para o conceito de leitura o que é de cada um, a singularidade da interpretação de cada um, o que é próprio de cada um, nessa relação com a leitura de um texto. Por outro lado, o trabalho do sujeito também é introduzido aqui: isto é, a possibilidade de construção, de criação, de interpretações outras que não exatamente as esperadas por quem escreve ou por quem ensina. Enxergar essa perspectiva é abrir brecha para a não exatidão do significado, para a não exatidão das respostas, é admitir o universo das possibilidades. É poder sair da posição de aceitar uma única resposta para enxergar as várias respostas possíveis que um sujeito é capaz de produzir na aventura do conhecer.

Vale ressaltar que essa percepção do leitor como condutor de sua própria leitura, ou seja, de poder ler o que ninguém mais talvez possa, adentrando as palavras, de uma forma singular, não significa dizer que não se tenha, em certos momentos, no processo de ensino, de dar conta de uma leitura voltada apenas para a avaliação de habilidades, uma leitura a ser feita para assim extrair significados e conceitos, por exemplo. O que o estudo pretende é introduzir a possibilidade de ampliar a concepção sobre esse ato, de enxergar outras formas de elaboração, de admitir um sujeito dentro desse processo de leitura.

Bem, trazer esse sujeito, que não é passivo, e que não é igual a todos, para o espaço da leitura e, consequentemente, da aprendizagem, permite ousar dizer, ainda, que a decodificação 
das palavras, como foi descrita anteriormente, seria apenas uma etapa desse processo, sendo que, não necessariamente, as crianças que ainda não são capazes de fazê-lo, por exemplo, não teriam também a sua forma de leitura.

A criança da Educação Infantil, da qual se trata aqui, vai fazendo, ao longo desse período, suas leituras de histórias, de livros, de mundo. Durante esse processo, vai colocando na sua bagagem os momentos em que ouvia histórias contadas por alguém, as imagens desses enredos, a repetição dessas histórias, construindo a sua relação com esse objeto. Mais à frente, esses conteúdos vão permitindo a construção do leitor que, então, poderá sair da posição de ouvinte, embora não passivo, para a posição de quem poderá questionar, indagar e perceber a própria formação como leitor.

\author{
Lendo o mundo das maravilhas \\ Histórias não garantem a felicidade nem o \\ sucesso na vida, mas ajudam. Elas são como \\ exemplos, metáforas que ilustram diferentes \\ modos de pensar e ver a reatidade e, quanto \\ mais variadas e extraordinárias forem as \\ situações que elas contam, mais se ampliará a \\ gama de abordagens possiveis para os problemas \\ que nos afligem. Um grande acervo de \\ narrativas é como uma boa caixa de \\ ferramentas, na qual sempre temos o \\ instrumento certo para a operação necessária, \\ pois determinados consertos ou instalações só \\ poderão ser realizados se tivermos a broca, o \\ alicate ou a chave de fenda adequados. (CORSO; \\ CORSO, 2006, p. 33)
}

Retomando os contos infantis, parece possível sustentar o pressuposto de que tais histórias podem ser entendidas como instrumentos importantes para o reconhecimento das crianças da Educação Infantil como leitoras, na medida em que atendem à imensidão de sentidos que elas buscam ao longo de seu processo de elaboração de respostas indispensáveis à leitura de seu lugar no mundo e de sua relação com o outro. O que equivale a dizer que o conceito de aprendizagem não pode ser compreendido sem a compreensão do conceito de subjetividade. 
Anteriormente foi introduzido o conceito de leitura; um sujeito que não é passivo, que deseja e se movimenta na direção de um caminho que procura. Dessa forma, introduziu-se a questão da subjetividade, permitindo falar de algo que vai além do que fica no aparente e no visível, que tem a ver com a verdade do sujeito, algo que diz sobre ele e na direção do quê ele faz a sua trajetória, inclusive na busca do objeto de conhecimento.

Cabe, agora, interrogar: o que as crianças pequenas, as da Educação Infantil, estariam a buscar? Pelo que se sabe, elas buscam algo que é comum a todas, em se tratando do que as interessa em relação, por exemplo, à sua faixa etária. Sabemos que as crianças gostam de brincar, de se lambuzar, de fazer castelinhos de areia, de ser super heróis, de imitar animais, de jogar, de ouvir estórias, de perguntar, de aprender. É comum a todas elas vivenciar essas situações. Se não houver algo da ordem do real do corpo, na dimensão orgânica, que impossibilite o seu desenvolvimento considerado normal, provavelmente, todas elas gostariam de experienciar esses momentos. Mas é só isso?

Piaget contribui para o entendimento do pensamento da criança, com a Epistemologia Genética. Através dos seus estudos, podemos encontrar respaldo para entender o modo como a criança opera mentalmente, que recursos ela utiliza para responder a questões da ordem do conhecimento. São perguntas do tipo: Por que esse é maior? Onde tem mais? São iguais? Quantos objetos temos aqui? Tais indagações estão presas à racionalidade, à objetividade, à cognição. O que podemos concluir é que, segundo esse autor, há um processo que é geral a todas as crianças, que elas vão desenvolvendo, construindo, através da interação com o objeto de conhecimento.

Mas, para o tema em discussão, chegar a essa conclusão é suficiente? Sem dúvida, há algo no que está sendo investigado que remete a esse registro geral. Mas há também o que não responde a esse geral e que exige caminhos outros a serem percorridos. Há algo que aqui se busca fora do que é comum, do que é esperado. Por exemplo: uma criança, aproximadamente, aos dois anos, atinge a capacidade de fazer de conta, de brincar que é bruxa, super-herói, mãe, gato, princesa - o que chamamos a capacidade de entrada no simbólico ${ }^{2}$. Esse é um acontecimento esperado. Como explicar, porém, os questionamentos do tipo: quero ser princesa e não quero ser bruxa, quero ser gato, mas
2) O termo simbólico está

empregado aqui com a conotação que lhe atribui Piaget ao referir-se ao estágio pré-operatório, no qual a criança começa simplesmente distinguir o significante do 
significado, isto é, que os objetos apresentam determinadas palavras, e que estas podem ser usadas em lugar do objeto. não cobra; quero ser a Cinderela? Identificamos vários recursos, muito específicos, além das histórias e dos contos infantis, e que fazem parte de gama de produções imaginárias que a criança "tira da manga", "de dentro da cartola" para dar conta, por si mesma, de suas indagações, em diversos momentos da sua infância. Não lhes caberia recorrer às explicações formais dos adultos, porque essas não sanariam as suas inquietações. É por tomar a própria via de solução encontrada pelas crianças que o estudo busca apoio nos contos infantis.

Se fizermos uma volta ao passado, na tentativa de buscar a origem das histórias infantis, os contos de fadas, encontraremos registros na França, como a tradição oral camponesa, no século XVII, por exemplo. Naquela época, os contos serviam como instrumentos capazes de ajudar aqueles povos a enfrentarem situações reais da sua vida, como a fome, a morte, a crueldade, os fenômenos da natureza, a violência, etc. Os elementos constitutivos de tais contos os transformavam em histórias mais "cruéis", do que as formações posteriores, mais modernas, não tendo uma preocupação com o final feliz, ou um "felizes para sempre".

No século XIX, já era perceptível a existência dos contos de fadas, em suas versões modernas, ou seja, apresentados com algumas alterações nos seus enredos, acrescidos de ricos elementos simbólicos e de significações inconscientes. De alguma forma, com modificações, ou não, parece que algo permanece na história desses contos que os tornam "imortais", se assim podemos classificá-los. O que será que ecoa como respostas nessas crianças pequenas? O que dizem sobre elas?

Bruno Bettelheim, em seu livro, A psicanálise dos contos de fadas, afirma que os contos tradicionais são importantes para a construção da subjetividade. Ele explica:

\footnotetext{
Para que uma estória realmente prenda a atenção da criança, deve entretê-la e despertar sua curiosidade. Mas para enriquecer sua vida, deve estimular-lhe a imaginação, ajudá-la a desenvolver seu intelecto e a tornar claras suas emoções; estar harmonizada com suas ansiedades e, ao mesmo tempo, sugerir soluções para os problemas que a perturbam. (BETTELHEIM,1980, p. 13)
}

Dessa forma, poderíamos dizer que os contos sobrevivem até hoje, porque as crianças também existem até hoje. As crianças pequenas passam por etapas, no que diz respeito ao seu 
desenvolvimento intelectual, ou seja, partem de formas mais concretas de pensamento para outras mais elaboradas e, posteriormente, mais abstratas. Para o que nos interessa, aqui, significa dizer que, inicialmente, para entender, responder a questões que elas se fazem, ao longo da sua subjetividade, elas precisam experienciar a fantasia ${ }^{3}$, a possibilidade que o imaginário proporciona de responder a esses questionamentos de uma outra forma.

Ainda em A psicanálise dos contos de fadas, Bruno Bettelheim (1980, p. 61) acrescenta: "[...] Todavia, as explanações realistas são usualmente incompreensíveis para as crianças, porque lhes falta a compreensão abstrata requerida para que façam sentido para elas".

Como é sabido, a produção imaginária da infância interessa à psicanálise e, particularmente, aos psicanalistas de crianças, cujos olhar e escuta se detêm nos variados recursos imaginários utilizados pelos pequenos sujeitos em estruturação, tentando dizer, por meio dos jogos e das brincadeiras de faz de conta, o que ainda não podem articular através do discurso formal produzido culturalmente.

Silvia Molina (1996) destaca como recursos imaginários que, a seu ver, são acionados pelas crianças, nessa dramática tentativa de responder às cruciais perguntas que vão se fazendo, ao longo da constituição de sua subjetividade, os jogos do "Fort - da", os corporais e o jogo de esconde-esconde; os objetos transicionais, as brincadeiras de cair, a repetição no brincar e no desenho; os amigos imaginários e a identificação imaginária com heróis e super-heróis; os cantos e contos infantis; o fascínio por ouvir o relato sobre sua história e manuseio dos álbuns de fotografias e filmes sobre sua vida, etc; as teorias sexuais infantis, os medos e as fobias, assim como a mentira, os devaneios e a invenção de histórias. (MOLINA ,1996, p. 16-17)

$\mathrm{Na}$ verdade, os contos infantis possibilitam a criança entrar no mundo da fantasia, do imaginário, e poder elaborar respostas a questionamentos quanto à sua subjetividade, de uma forma possível, em relação à sua capacidade cognitiva. Mergulhar naquele mundo de fadas e de maravilhas permite encontrar-se com o imaginário, que é fundamental e importante para o arcabouço que vai se formando, posteriormente, nesse sujeito. Essas vivências com os contos vão thes dando a possibilidade de
(3) Fantasma ou fantasia (alem: Phantasie; fantasme; ing:. Fantasy ou phantasy). Para S. Freud, representação, argumento imaginário,consciente(devaneio), pré-consciente ou inconsciente. preconsciente ou inconscient implicando um ou varios personagens, que coloca em cena um desejo, de forma mais ou menos disfarçada. O fantasma é, ao mesmo tempo, efeito do desejo arcaico inconsciente e matriz dos desejos atuais, conscientes e inconscientes. Continuando Freud, J. Lacan destacou a natureza essencialmente de linguagem do fantasma. Também demonstrou que seus personangens valiam nele muito mais por certos elementos isolados(palavras, fonemas e objetos associados, partes do corpo traços de comportamento,etc) do que por sua totalidade. Irá propor o seguinte matema: \$ punção a, que se Lê "S barrado punção de a". Este matema designa a relação particular de um sujeito do inconsciente, barrado e irredutivelmente dividido por sua entrada no universo dos significantes, com o objeto pequeno a, que constitui a causa inconsciente de seu desejo.
(CHEMAMA, 1995, p.70-71) 
responderem a questões relativas à sua origem, formulando hipóteses sobre: De onde eu vim? Como nasci? (que levam à construção de teorias sexuais); Quem sou eu? Como me reconheço? (que se referem à filiação e à identificação); O que é ser menino (a)? , O que o menino tem que a menina não tem? (que dizem respeito à diferença sexual).

Essas questões são cruciais para as crianças e, ao longo da sua infância, vão sendo respondidas. Essas são perguntas que acontecem antes das perguntas que dizem respeito ao conhecimento. Esses questionamentos aparecem antes do surgimento da curiosidade de responder àqueles outros ligados a noções de maior $\mathrm{X}$ menor, grande $\mathrm{X}$ pequeno, muito $\mathrm{X}$ pouco. Tais questões dizem sobre o saber do sujeito, ao que é próprio de cada um, e ainda arriscaríamos dizer também ao que se busca nas entrelinhas, por exemplo, de um texto.

Para as crianças pequenas, ter acesso aos contos infantis lhes permite também entrarem em contato com o mundo da imaginação que abre, além do que já foi explanado, a possibilidade de entrarem em contato com aprendizagens que fazem parte de um campo, ainda de construções de "armados" que, mais tarde, servirão de "terreno" para outras aprendizagens mais elaboradas. Ousaríamos, então, indagar: e para a formação dessas crianças como leitoras, o que acrescentaria?

Parece válido afirmar, ainda, que os contos infantis fazem parte das histórias de leituras das crianças que, ao longo da sua infância, vêm se deleitando com as maravilhas dos Irmãos Grimm, Perrault ou Andersen, e que essas histórias são mais uma possibilidade de caminho que elas podem percorrer para dar conta de suas elaborações, através da fantasia, recurso único possível, nesse momento de sua estruturação psíquica. Para se tornarem sujeitos leitores, mais tarde, basta que o necessário trânsito entre saber e conhecimento tome o seu curso natural; o que só será possível se a primeira leitura for pronunciada por um sujeito que um dia pôde ouvir histórias. "[...] Ouvir histórias é um dos recursos de que as crianças dispõem para desenhar o mapa imaginário que indica seu lugar, na família e no mundo." (CORSO; CORSO, 2006, p.18) 


\section{A subjetive thread that sew a childhood}

Abstract: What would lead children, who are not reading yet to being interested in fairy tales? Is there any reading possibility that goes beyond decoding letters and words? What kind of reading would be this? What would these children be reading in these texts? Could we consider them readers? These are basic questions addressed by this text which aims to discuss the interest of children in fairy tales. In order to discuss this issue, some steps are fundamental, such as: to define concepts of reading and readers, to establish a relation between imagery and reading stories, and consequently, the importance of these aspects for learning and the construction of subjectivity. Key words: Reading. Children imagery. Subjectivity.

\section{Referências}

BETTELHEIM, Bruno. A psicanálise dos contos de fadas. Rio de Janeiro: Paz e Terra, 1980. 366 p.

CORSO, Diana L.; CORSO, Mário. Fadas no divã: psicanálise nas histórias infantis. São Paulo: Artmed, 2006. 326 p.

CHEMAMA, Roland. Dicionário de psicanálise. Porto Alegre: Artes Médicas, 1995. 240 p.

LACAN, Jaques. Os escritos técnicos de Freud: seminário 1953 1954. 3. ed. Rio de janeiro: Jorge Zahar, 1986. 336 p.

LAJOLO, Marisa. Do mundo da leitura para a leitura do mundo. 6. ed. São Paulo: Ática, 2005. 111 p.

LAJONQUIÈRE, Leandro de. De Piaget a Freud: a (psico)pedagogia entre o conhecimento e saber. Petrópolis, RJ: Vozes, 1993. 253 p.

MARTINS, Maria Helena. O que é leitura. 7.ed. São Paulo. Brasiliense, 1986. $94 \mathrm{p}$.

MOLINA, Silvia. A pequena criança da psicopedagogia inicial. Escritos da criança, Porto Alegre, n.5, p. 15-20, 1996.

ORLANDI, Eni Puccinelli. Interpretação: autoria, leitura e efeitos do trabalho simbólico. Campinas: Pontes, 2004. 156 p.

PERRAUlT, Charles. Contos de Perrault. Belo Horizonte-Rio de Janeiro: Villa Rica, 1994. 290 p.

PIAGET, Jean. A epistemologia genética. Tradução Nathanael C. Caixeiro, Zilda Abujamra Daeir e Célia E. A. Di Piero. 2. ed. São Paulo: Abril, 1983. p. 2-64. (Os Pensadores)

SANCHES NETO, Miguel. Herdando uma biblioteca. Rio de Janeiro: Record, 2004. 140 p. 